\title{
Old-growth forest values: A narrative study of six Canadian forest leaders
}

\author{
by Joanne M. Moyer ${ }^{1}$, Peter N. Duinker ${ }^{2}$ and Fay G. Cohen²
}

\begin{abstract}
Old-growth forest is the subject of widespread conflict. Understanding associated values and attitudes in society is necessary for its sustainable management. We investigated old-growth values through a narrative study employing in-depth interviews with six leaders in Canada's forest sector. Old-growth forest was valued for its natural ecological systems, biotic components, and experiential aspects. The study highlights the importance of value discourse within the forest sector.
\end{abstract}

Key words: old-growth forest, values, Canada, forest management

\section{RÉSUMÉ}

Les vieilles forêts sont au cœur d'un conflit généralisé. La compréhension des valeurs et des attitudes associées à ces forêts est requise pour pouvoir réaliser leur aménagement durable. Nous avons étudié les valeurs reliées aux vieilles forêts à partir d'une analyse narrative des entrevues en profondeur réalisées avec six chefs de file du secteur forestier du Canada. Les vieilles forêts sont estimées pour leurs systèmes écologiques naturels, les composantes biotiques et leurs possibilités expérientielles. Cette étude souligne l'importance de la notion de valeur exprimée par le secteur forestier.

Mots clés : vieilles forêts, valeurs, Canada, aménagement forestier

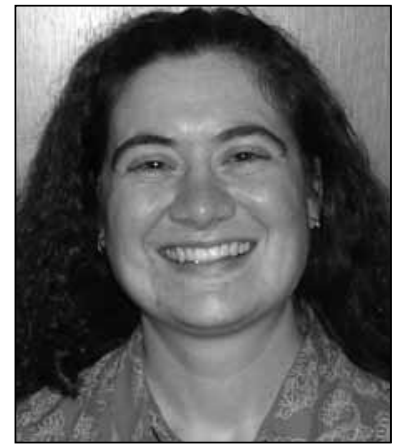

Joanne M. Moyer

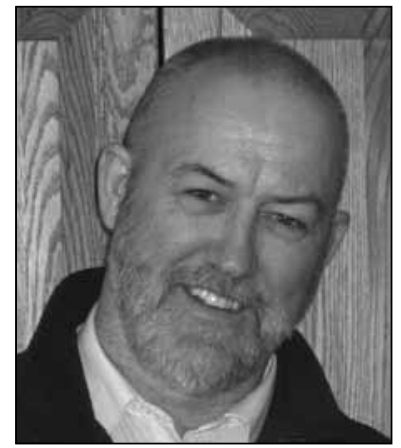

Peter N. Duinker

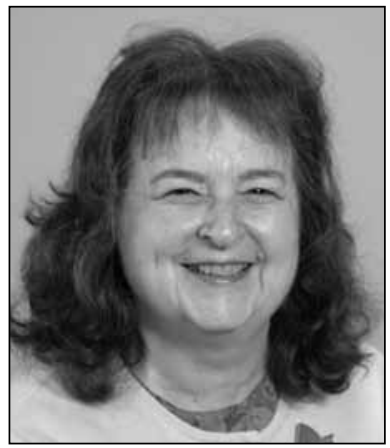

Fay G. Cohen

finding solutions will require that all three be addressed.

The research described in this paper was one of two studies (Moyer 2006, Owen 2006, Moyer et al. 2008) ${ }^{3}$ that explored the social dimension of OGF management within a larger study addressing all three domains discussed above. From within the social domain, these studies focussed on values and attitudes. Values and attitudes are at the core of individual and societal functioning (Bengston et al. 2004), providing a standard by which

\section{Introduction}

Old-growth forest (OGF) is the subject of profound and widespread conflict in North America. Disagreements over OGF management and use have precipitated numerous lengthy conflicts in recent decades, of which Temagami, Ontario (1989), Clayoquot Sound, British Columbia (1993), and Main River, Newfoundland (early 2000s) are three notable Canadian examples. The roots of OGF conflicts are complex and varied, including ecological, economic, and social issues. These three domains, which are often described as the three pillars of sustainable development (Holling et al. 1998), are deeply inter-related within OGF conflicts, and

decisions and behaviours are evaluated and thereby helping to determine how people choose to act (Rokeach 1973, Dietz et al. 2005). As such, values and attitudes are fundamental to many environmental and forestry conflicts (Brown and Reed 2000), which are shaped by differences in values and in understandings of how human beings should relate to their

\footnotetext{
${ }^{3}$ These studies were undertaken through the Master of Environmental Studies program at Dalhousie University, with funding from the Sustainable Forest Management Network and the Social Sciences and Humanities Research Council.
}

\footnotetext{
${ }^{1}$ School for Resource and Environmental Studies, 6100 University Ave., Dalhousie University, Halifax, Nova Scotia B3H 3J5. Current address: Natural Resources Institute, Clayton H. Riddell Faculty of Environment, Earth, and Resources, University of Manitoba, Winnipeg, Manitoba R3T2N2. E-mail: ummoyerj@cc.umanitoba.ca

${ }^{2}$ School for Resource and Environmental Studies, 6100 University Ave., Dalhousie University, Halifax, Nova Scotia B3H 3 J5.
} 
environment (Steel and Lovrich 1997). Consequently, gaining a deeper understanding of values and attitudes, and incorporating this understanding into the decision-making process, can help managers and policy-makers to improve their decisions, and can thereby help both to avoid conflicts and to mitigate them more effectively when they do occur (Bengston 1994, O’Brien 2003, Bengston et al. 2004).

The purpose of this research was to explore the values, attitudes and actions, with respect to OGF, of leaders in Canada's forest sector. The study examined the content of the OGF discourse in Canada, as reflected in their narratives. Drawing from these narratives, this paper describes the aspects of OGF that were valued, and explores the grounds for this valuation. A value was defined as that which is desirable (Harman 2000, Dietz et al. 2005), encompassing both held values, which are preferred end-goals, principles and modes of conduct (Rokeach 1973), and assigned values, which describe the worth ascribed to objects (Beckley et al. 1999).

\section{Methods}

Six leaders in the forest sector were studied in-depth, using a qualitative, narrative approach. Leaders were chosen as the focus because they represent a unique segment of society. Through their involvement in forest issues, they could be expected to have a well-developed and articulated set of values and attitudes toward OGF. They are also important sources of societal values and attitudes through the influence they wield over management, policy, and public opinion. Finally, through their work, they demonstrate how these values and attitudes translate into action and are incorporated into various aspects of the social system. Given these defining traits, leaders in the forest sector provide unique insights into values, attitudes and opinions and their role in managing OGF.

Potential participants in the Canadian forest sector were identified as leaders based on the significance of their contributions to forest management, policy and practice through involvement in industry, government, academia, activism or publication. We aimed to gain a rich set of perspectives by assembling a diverse group of individuals drawn from the various interests and perspectives, recognizing that with such a small sample size, it would be impossible to represent all the existing interests and perspectives. Using a purposive sampling strategy (Merriam 1988), we selected participants based on their level of experience and influence in the field, connection to OGF, role in the forest sector, geographic location and cultural perspective, and gender. Potential participants were approached through a careful and respectful process involving an initial contact by a member of the research team with whom they were acquainted, ${ }^{4}$ followed by an e-mail and tele-

\footnotetext{
$\overline{{ }^{4} \text { All but one participant were acquaintances and/or colleagues of }}$ the team member (PND) who made the introductions. While this approach was intentionally adopted to facilitate access to the participants, it introduced the possibility of bias in the form of yielding a group of participants with a tendency toward similar positions and ideas. We actively sought individuals with different perspectives, and the people who were ultimately selected, and the perspectives they provided, exhibit sufficient variability to indicate the appropriateness of our approach. Furthermore, the forest community in Canada is small, and PND has engaged in forest management and policy work nationwide, so it would have been difficult to find people whom he does not know.
}

phone call from the lead author. The final group of participants reflected our goal of diversity for most of these criteria, as illustrated in Table 1.

Three interviews, of 45 to 90 minutes each, were conducted with each participant as the primary source of data. The lead author traveled to meet the participants at their place of work, spending several days at each location. Interviews took place between November 2005 and February 2006 and were audio-recorded. The structure and content of the interviews were based on an adaptation of Seidman's (1998) three-interview approach, focussing on the participant's context and background, his or her activities in the forest sector, and the values and attitudes that have informed and given meaning to participants' actions and behaviours.

Formal data analysis for the project took place in two stages. The first involved the creation of narrative descriptions in the form of a personal profile of each participant. ${ }^{5}$ In the second stage of analysis, the data were coded for patterns and themes using NVivo ${ }^{\mathrm{TM}}$ software (Rubin and Rubin 2005).

\section{OGF Values}

In the following section, we describe our findings, beginning with a brief discussion of OGF definitions, and then provide a general overview of participants' attitudes toward OGF. Finally, we outline the key features of OGF that were valued, discussing how these features were perceived and why they were deemed desirable.

Defining OGF as a universal term is problematic due to variations in forest type, location, development processes and disturbance patterns. A rich discussion exists within the literature on this subject (Hunter 1989, Franklin and Spies 1991, Duchesne 1994, Hunter and White 1997, Spies 2004), but given the geographic differences among the study participants, we chose not to impose one definition on the study. Instead, participants were invited to state their own definition of OGF. Two approaches were taken by the participants, basing their definitions on either the degree of disturbance within the forest or on particular structural and process features (Table 2).

The six participants expressed a range of attitudes about the importance of OGF. Husband, Drescher and VanDusen all affirmed the vital role that OGF plays in the forest and affirmed it as a priority issue. Kimmins was also supportive of the issue, though tempering his support with an equal degree of support for other forest conditions. Smith and Schleifenbaum viewed OGF as simply one forest condition which has perhaps been given greater attention than it deserves, to the detriment of other issues. Despite these differences, all the participants identified uses, characteristics and qualities of OGF that they valued, and there was a great degree of similarity in what they identified as most important. While these shared values were expressed by all participants (unless otherwise noted), the relative weight they were given by each participant varied (Table 2).

\section{Natural ecological processes}

A key feature of OGF valued by the participants was the natural ecological processes of the forest. The processes themselves were deemed important, but it was the natural state of

${ }^{5}$ These profiles are presented in full in Moyer (2006). 
Table 1. Recruited participants ${ }^{\mathrm{a}}$

\begin{tabular}{|c|c|c|c|}
\hline Participant & Location & Role in forest sector at the time of the study & OGF connection \\
\hline George VanDusen & $\begin{array}{l}\text { Corner Brook, } \\
\text { Newfoundland }\end{array}$ & $\begin{array}{l}\text { Forest Management Superintendent for Corner } \\
\text { Brook Pulp and Paper. }\end{array}$ & $\begin{array}{l}\text { Managed the company's response to } \\
\text { controversy over harvesting OGF in } \\
\text { Main River watershed. }\end{array}$ \\
\hline Jim Drescher & $\begin{array}{l}\text { New Germany, } \\
\text { Nova Scotia }\end{array}$ & $\begin{array}{l}\text { Owner and manager of Windhorse Farm, a } 60 \text {-hectare } \\
\text { woodlot and organic vegetable garden operation. }\end{array}$ & $\begin{array}{l}\text { Uses OGF as a benchmark, to } \\
\text { manage forest to maintain as many } \\
\text { characteristics of an unharvested } \\
\text { Acadian forest as possible. }\end{array}$ \\
\hline Peter Schleifenbaum & $\begin{array}{l}\text { Haliburton, } \\
\text { Ontario }\end{array}$ & $\begin{array}{l}\text { Owner, director and manager of Haliburton Forest, } \\
\text { a multi-use forestry, recreational and educational } \\
\text { operation. }\end{array}$ & $\begin{array}{l}\text { Haliburton Forest contains some } \\
\text { OGF stands. }\end{array}$ \\
\hline Peggy Smith & $\begin{array}{l}\text { Thunder Bay, } \\
\text { Ontario }\end{array}$ & $\begin{array}{l}\text { Lecturer at Lakehead University and first female } \\
\text { Aboriginal Registered Professional Forester in } \\
\text { Canada. }\end{array}$ & $\begin{array}{l}\text { Studied the Temagami OGF dispute } \\
\text { for her undergraduate honours } \\
\text { thesis. }\end{array}$ \\
\hline Hamish Kimmins & $\begin{array}{l}\text { Vancouver, } \\
\text { British Columbia }\end{array}$ & $\begin{array}{l}\text { Professor of forest ecology at the University of } \\
\text { British Columbia. }\end{array}$ & $\begin{array}{l}\text { Has written several articles and a } \\
\text { book chapter discussing OGF. }\end{array}$ \\
\hline Vicky Husband & $\begin{array}{l}\text { Victoria, } \\
\text { British Columbia }\end{array}$ & $\begin{array}{l}\text { Volunteered as an environmental advocate with } \\
\text { the Sierra Club of Canada for } 25 \text { years. }\end{array}$ & $\begin{array}{l}\text { Involved in many campaigns to } \\
\text { protect coastal temperate } \\
\text { rainforest in BC. }\end{array}$ \\
\hline
\end{tabular}

\footnotetext{
${ }^{a}$ Given the narrative approach of the research and the high-profile nature of the participants, it was impossible to ensure participant confidentiality and anonymity. Participants agreed to have their identities revealed through the use of their names, direct quotations from their interviews, and direct mention of their work and publications. The study was approved by the Research Ethics Board for the Humanities and Social Sciences at Dalhousie University and participants were given the opportunity to review and comment upon both their interview transcripts and their personal profiles.
}

their functioning that was paramount. The natural state, or the absence of human disturbance, not the specific age of the forest, seemed to be an important part of what made it unique and valuable. This is evident in the fact that three of the six participants defined OGF by referring in some way to the degree of human disturbance in the forest rather than its age or characteristics (Table 2). Several of them, Husband in particular, also tended to make comparisons between OGF and managed or second-growth forests, rather than comparing OGF and young forests.

At the same time, there was some discussion about the meaning of absence of human disturbance and whether such a condition even exists. Both Drescher and Smith recognized that just by entering a forest, a human being is causing a certain degree of disturbance. Smith also noted that Aboriginal peoples have been living in and using Canada's forests from time immemorial, which couches the idea of human disturbance or the lack thereof in a completely different context. Nonetheless, there seemed to be a general consensus that a lack of human disturbance means, at the least, an absence of industrial development. Furthermore, Drescher offered a description that seems to resonate with the way in which others were using the term, defining a relatively undisturbed situation as

"...something that is within that dynamic balance

that has an historical context [...] that kind of dynamic balance that has developed over a long period of time through the evolution of that community and the individuals within that community and the species within it."

There were two reasons for which these natural ecological processes that exist in OGF were valued. First, as reference points or benchmarks, they provide a useful tool for management. In managing forests for timber products and other human uses, society desires healthy and productive forests that will continue to provide these benefits. Perceptions of forest health change over time, but for the study participants in the current context, there was a strong connection between health and the natural function of an unmanaged forest. When asked to define a healthy forest, nearly all of the participants referred in some way to naturally functioning forest processes. For example, VanDusen described a healthy forest as

"...one where the ecological processes are functioning as they should: the nutrient cycling, the carbon cycle, and growth rates are healthy and processing...” Similarly, Schleifenbaum defined a healthy forest as

"...a forest that can perpetuate itself in every aspect.

The basic structure of the forest are the trees, but the trees are also providing a lot of other values-wildlife values, and floristic values-and as long as a forest on its own or under human management can provide all these values in perpetuity, let the forest grow, let the forest reseed itself, grow up, grow into mature trees. It can provide all these values and that's how I would compare a forest to be healthy."

Kimmins talked about the balance between disturbance agents, such as disease, and ecological processes, such as photosynthesis and nutrient cycling, being appropriate to the age of the forest. Husband referred to natural systems following their natural course. Drescher made the most explicit link between healthy forest and the natural processes of an OGF by stating: 
Table 2. OGF perspectives of six forest-sector leaders

\begin{tabular}{ll}
\hline Participant & Definition of OGF \\
\hline George VanDusen & - natural system undisturbed by human development \\
& - forest has gone through one successional rotation \\
& - age isn't important \\
& preferred term: natural forest
\end{tabular}

Jim Drescher

- forest that is undisturbed by humans

- dynamic stability not interrupted by human activity

- forest has never seen an axe

Peter

Schleifenbaum

- forest with OG features: age, size, decay

Peggy Smith

- forest that has reached maturity without being affected by human interference and will continue to exist naturally

- by this definition, true OGF does not exist

Hamish Kimmins

- OGF is a feeling, a social construct

- uses index of old-growthness based on criteria of characteristics

Vicky Husband - OGF structure: $\underline{b i g}$, old trees, gaps, small trees coming up, snags, downed trees
OGF values $^{\mathrm{a}}$

ecological processes, benchmark, biodiversity, undisturbed/natural state, wildlife, beauty, impressive scenery, the economy, wood supply, jobs, tourism, uniqueness, forest structure, public education, size of trees, inherent worth

perspective/insight, benchmark, carbon sink, life, biodiversity, peace/harmony, spiritual, natural/ undisturbed state, ecological services, air quality, wildlife, beauty, impressive scenery, size of trees, ethical, age of trees

biodiversity, non-fibre (includes diversity, habitat, aesthetics, etc.) life, wildlife, natural/undisturbed state, timber/wood products, uniqueness, public education, beauty (?), size of trees, peace/harmony

"the people," part of landscape diversity, natural/ undisturbed state(?), wildlife, beauty, impressive scenery, inherent worth, spiritual(?), perspective/insight, peace/ harmony, age

insight/perspective, genetic diversity, recreation, beauty (?), size of trees, spiritual, peace/harmony, timber/wood products, energy, the economy, jobs, benchmark, ecological processes, natural/undisturbed state (?), age, wildlife (?), cultural, heritage

life, wildlife, natural/undisturbed state, ecosystem services, legacy/heritage, beauty, water, air, carbon sink, tree size, biodiversity, uniqueness, forest structure, impressive scenery, spiritual, timber/wood products, medicine, jobs, tourism, cultural, Aboriginal, recreation, inherent worth, age, rare

\footnotetext{
aThis column lists all the values mentioned throughout the course of the interviews by each participant. Values in bold italics indicate those stated in response to questions about what is valued most highly about OGF. In italics are those values we interpreted to be of special importance based on the frequency and/or intensity of their statement. Question marks indicate values that were mentioned in a context of doubt, e.g., this value is not unique to OGF, or does not always exist in OGF.
}

"...the forest is healthy if it exhibits most of the characteristics of an old-growth forest for that type..."

While they were also careful to clarify that OGF is not the only healthy forest condition, it is clear that for many of them, OGF, by virtue of its lack of anthropogenic disturbance, represents an example of forest health and is therefore an important benchmark for managed forests. This point was stressed most strongly by VanDusen, as well as by Drescher whose entire approach to forestry revolves around managing his forest to resemble his OGF reference point. This view is shared by others in the literature (Frelich and Reich 2003), including ecologist Herb Hammond (1993: 47), who describes OGF as a "...touchstone to past forests, the zenith of today's forests, and the biological legacy for future forests," and Hendrickson (2003: 651), who states that

"...old-growth forests are highly desirable sites for research, monitoring, and adaptive management. They are living laboratories of adaptive evolution, and invaluable gene repositories. They can be used to test hypotheses about complexity, stability, resilience, and ecosystem change."

The second reason that natural ecological processes were valued was for the environmental services they provide, such as water quality, flow and temperature control, air quality, oxygen production, and carbon sequestration. On this last point, there was some disagreement-while both Drescher and Husband referred to their capacity as carbon sinks as a reason for OGF protection, Kimmins argued that since OGF grows slowly and is no longer sequestering large volumes of carbon, keeping forest in an OGF state is not the best way to maximize carbon absorption. Instead, he recommended that OGF be harvested, making sure to use the wood for long-lasting products like furniture, and the waste as bio-fuel. Then a young forest, which removes carbon from the atmosphere more efficiently, should be grown in its place.

Regardless of these details, five out of the six participants stated explicitly that humans are dependent on nature and that nature is better at providing these services than are humans. In Kimmins' words,

"...we are a species that depends upon nature, and if

we took nature away, we can't just engineer everything,

we can't provide the environmental services that natu-

ral ecosystems provide."

While OGFs are not the only forests, or the only natural ecosystems that provide environmental services, several participants (Husband and Drescher in particular) valued this 
aspect of OGF highly. It is also recognized in the literature that "...the capacity of old-growth forest to provide ecosystem services may be far more important to society than their use as a source of raw material" (Hendrickson 2003: 650).

\section{Biotic components}

A second characteristic of OGF that was highly valued was its set of biotic components. Husband described the abundance of life in OGF, and Husband, Kimmins, Schleifenbaum and VanDusen referred more specifically to the wildlife and other species that depend on the specific structure and characteristics of OGF for habitat and food (Kimmins 2003). At the same time, Kimmins suggested the possibility that some species are not as dependent on OGF as is currently believed, particularly if timber-harvest techniques can be adapted to retain certain structural features of OGF.

The value of the biotic components received the greatest consensus in the concept of diversity or biodiversity. Once again some doubt was expressed as to whether OGF is always more diverse than other forest conditions, and the meanings of diversity varied. Both VanDusen and Kimmins stressed that OGF in Canada does not necessarily have high species biodiversity, but identified genetic diversity and structural diversity as its particular strengths. Genetic diversity is also frequently cited in the literature as a unique and valuable attribute of OGF (Frelich and Reich 2003, Hendrickson 2003, Mosseler et al. 2003a). Smith referred to OGF as an aspect of diversity in forest conditions on the landscape, and Schleifenbaum, Drescher and Husband spoke more broadly about the diversity of life and conditions in the forest.

The biotic components of the forest were valued for three reasons. First, from a biological perspective, all species play a role in the web of life, and together contribute to the dynamic stability and the balance of the ecosystem. Biodiversity is “....an indicator of the health of an ecosystem, and a portent of its ability to survive future stresses" (Vanderlinden and Eyles 2000: 238). Husband described this aspect of OGF as

"...that whole intertwining structure of life that the for-

est maintains because of its structure and the way it is [...]

It's the whole wonderful web of life, because it is inter-

twined, and everything is dependent on other parts."

Similarly, Drescher talked about “...maintaining the structural and functional web of life in the forest, not causing harm and causing that web to unravel." This relates to the value of natural ecological processes and the health of the forest discussed earlier. Second, from a human-use perspective, the animals and trees provide food and wood products, as well as recreational enjoyment, while genetic diversity can be used for developing new varieties of trees in managed forests. For example, VanDusen stated:

"...wood is a fantastic product and a fantastic build-

ing material, and it's renewable, so I think there's a value in managing forests to provide products for society that society needs."

Alternatively, Smith noted that the Aboriginal community would talk about OGF "...in relation to their use of the land or their knowledge of the land, because it provides habitat for wildlife that they depend on for food or for trapping." Finally, from an ethical perspective, these creatures are part of the community of life and simply have a right to exist. Drescher spoke of this ethical imperative in terms of "... not wanting to harm the lives of other beings."

\section{Personal experiences}

A third set of values arose from the participants' personal experiences in OGF. Many of them expressed appreciation for the beauty and impressive scenery they associate with visits to OGF. This appreciation was conveyed in evocative terms, using words such as "majestic", "grandeur", and "spectacular", and was described through visual impressions, textures, smells, sounds and physical conditions. For Drescher and Schleifenbaum, beauty was associated with health, while for Smith, a feeling of wildness and lack of human intervention was important. Many of the participants noted that judgements of beauty are highly subjective. Some were also careful to state that OGF is not the only beautiful condition and that young forests and human-made parklands can also be visually appealing. In fact, the forests that VanDusen finds most beautiful are younger than OGF, and both Kimmins and Schleifenbaum noted that OGF can be messy and chaotic, and not particularly appealing in an aesthetic sense. Schleifenbaum further speculated that the forest condition that the public believes to be OGF and wishes to protect for its beauty is in fact a mature forest in the later stages, which has not reached the OGF stage. It is therefore important to recognize the distinction between the visual and ecological conditions of the forest when considering the aesthetic values of OGF-beauty does not necessarily correspond directly with health, and health does not necessarily correspond with beauty.

The experiential aspect of OGF also has a spiritual component. Drescher described this experience as "...the lack of separation between the forest itself and my own body and mind." Smith described how, in the quietness of the forest, she "...can all of the sudden turn outside of [herself]," and Husband expressed that the feeling of pristine nature "...just lifts your soul." Several of them also recognized, however, that the OGF condition is not necessary for spiritual experiences to occur in the forest.

More specifically, Drescher and Kimmins also talked about the feelings of peace, tranquility and harmony that they experience when in OGF. It was suggested that perhaps these feelings arise from the fact that, in some cases, we do not feel the need to care for the forest because it is taking care of itself and has been doing so for a very long time. This is a stark contrast to the busy, stressful and responsibility-filled lives of today's society. This assessment corresponds with Kimmins' understanding of the importance of OGF for recreation (Kimmins 1997). Feelings of peace and tranquillity also seem to have something to do with the particular physical conditions and qualities of OGF. Drescher described feelings of

"...tranquillity, or peacefulness, or calm-abiding, or settled mind, or vibrant and peaceful energy in an oldgrowth situation, and in a highly disturbed situation, not the opposite of all of those, but I think particularly [a] kind of agitation and anxious quality that people seem to have in a cutover, for example, or a plantation."

Similarly, Kimmins reflected that: "There is something about a very, very big tree, a very huggable tree, that makes your heart go pitter patter in a way that a small tree doesn't." For him, that something is "...a sense of longevity, hugeness and continuity, which instils a sense of peace within [him].”

Finally, the spiritual aspect of OGF was also described in terms of gaining insight or perspective through being in the forest. Smith described a stand of older trees near her cabin as 
“...a place to think, to be still, to relax, and to turn outside." Kimmins stressed the personal importance to him of the sense of proportion and continuity that he feels in the presence of big, old trees. Ultimately, Drescher described OGF as providing him the opportunity to wake up to the preciousness and impermanence of life, the consequences of his actions, and the reality of suffering in life.

The experiential aspects of OGF were valued for providing personal enjoyment, fulfilment and edification. Many of the participants remarked that these experiences can also occur in other forest conditions, and are sometimes stronger in younger forests, and even in managed forests. Yet there still seems to be something almost indefinable that is special for many people about the experience of being in OGF, especially those with very large trees.

\section{Heritage and people}

Two other types of values were less widely shared but deserve mention because of the emphasis they were given. The first is the idea of OGF as a heritage that we have received from the past that plays an important role in defining our country today, and as a legacy that we leave for the future. This was a key motivator for Husband in particular, and while both Kimmins and Schleifenbaum touched on these concepts in conjunction with their discussions of sustainability, it was Husband and Smith who emphasized the idea that forest is something we have received and must care for (though Smith was speaking more about the forest as a whole). It is interesting and possibly significant that these ideas resonated the most with the only two participants who were born and raised in Canada. They were also the only two women interviewed.

Finally, Smith identified the people who live in and depend on the forest as being the aspect of OGF she values most highly. While this value was unique to Smith, it is notable that most of the other participants recognized the importance of local communities and expressed concern about their well-being and the manner in which they are affected by the forest industry and the way forests are managed or conserved.

\section{Discussion and Conclusions}

This research revealed that three basic elements of OGF were valued as unique and special by the participants: natural ecological processes that serve as a reference point and provide environmental services; biotic components that are valued for economic, life-support and ethical reasons; and personal experiences that are valued aesthetically, spiritually, culturally and ethically. With a sample of six participants, these results cannot be generalized to the Canadian population as a whole and therefore cannot be used to determine how OGF management should proceed. Further research is required to discover how well these results correspond to the valuation of OGF in the broader population. At the same time, the management implications of this set of values can be considered.

A critical question is whether it is possible to manage an area of OGF to satisfy all these values simultaneously. The issue of human impact and disturbance is key in considering this. Some of the values or uses, such as reference points, environmental services, and life-support for some non-human species, are dependent on a forest situation that is not significantly altered by human activity. In contrast, economic uses and experiential uses produce varying degrees of disturbance.
It appears, then, that it may be necessary to organize OGF management in such a way that some areas have restricted human access, possibly even for recreational uses, while others are managed primarily for human visitation to serve aesthetic, spiritual and cultural values, and yet others are managed primarily for economic uses.

Several things should be considered when establishing different areas of OGF management. First, how undisturbed does a forest need to be to function as a reference point or to maintain diversity and wildlife? What degree of human disturbance is acceptable (Duchesne 1994)? How large a forest area is necessary to preserve the integrity of the "natural" OGF condition (Hendrickson 2003, Mosseler et al. 2003b)? What definition of OGF best ensures the protection of key ecological conditions (Duchesne 1994, Frelich and Reich 2003)? Furthermore, if strict limitations on human access are necessary on a large portion of the OGF landscape, what social and economic implications does this have? How would limiting human access affect conservation campaigns, which often use personal values and emotional attachments to galvanize public support? Can such attachments be formed without personal contact? Furthermore, is ecotourism, which is often touted as the economic driver that will replace the revenue and jobs that are lost from halting logging, a viable alternative?

At the same time, it is also prudent to consider how wise management can be used to maximize the expression of the whole range of values in all OGF areas. Various logging techniques are believed to be capable of maintaining the natural processes and habitat needs for OGF-dependent wildlife so that timber harvesting can occur while preserving other values (Kimmins 1997). This should be pursued further, so that even in OGF that is designated for economic uses, sensitive wildlife can survive and other environmental services be provided. It is also worth considering how harvesting techniques might be modified to maintain the features that enhance personal experiences in OGF. Furthermore, attention should be paid to ensuring that recreation and tourism activities also have a minimal impact on the forest ecosystem. Finally, aesthetic and spiritual values are highly personal and will therefore be expressed and experienced differently by different people in different forests. This must be taken into account when designing forest management for these values.

This brief discussion demonstrates how values can inform management considerations. The guidance they provide also contributes to reducing and resolving conflict. Sensitivity to values provides insight into priority areas that may trigger public dissension, and promotes the discovery of new opportunities and ideas. An understanding of values also allows decision-makers to anticipate public reactions to their decisions, to gain stronger public support for policies, and to transform conflict by uncovering fundamental sources of disagreement, and by revealing potential bases for consensus (Bengston 1994, O’Brien 2003).

\section{References}

Beckley, T.M., P.C. Boxall, L.K. Just and A.M. Wellstead. 1999. Forest Stakeholder Attitudes and Values: Selected Social-Science Contributions. Information Report NOR-X-362. Canadian Forest Service, Northern Forestry Centre, Edmonton, AB.

Bengston, D.N. 1994. Changing forest values and ecosystem management. Society and Natural Resources 7(6): 515-533. 
Bengston, D.N., T.J. Webb and D.P. Fan. 2004. Shifting forest value orientations in the United States, 1980-2001: A computer content analysis. Environmental Values 13(3): 373-392.

Brown, G. and P. Reed. 2000. Validation of a forest values typology for use in national forest planning. Forest Science 46(2): 240-247.

Dietz, T., A. Fitzgerald and R. Shwom. 2005. Environmental values. Annual Review of Environment and Resources 30: 335-372.

Duchesne, L.C. 1994. Defining Canada's old-growth forests - problems and solutions. The Forestry Chronicle 70(6): 739-744.

Franklin, J.F. and T.A. Spies. 1991. Ecological definitions of oldgrowth Douglas-Fir forests. In L.F. Ruggiero, K.B. Aubry, A.B. Carey and M.H. Huff (eds.). Wildlife and Vegetation of Unmanaged Douglas-Fir Forests. pp. 61-69. United States Department of Agriculture, Forest Service, Pacific Northwest Research Station, Portland, OR. General Technical Report PNW-GTR-285.

Frelich, L.E. and P.B. Reich. 2003. Perspectives on development of definitions and values related to old-growth forests. Environmental Reviews 11: S9-S22.

Hammond, H. 1993. Old growth, the zenith of forests. In G. Blouin and R. Comeau. Forestry on the Hill, Special Issue \#5 - Old Growth Forests. pp. 47-54. Canadian Forestry Association, Ottawa, ON.

Harman, G. 2000. Explaining Value and Other Essays in Moral Philosophy. Oxford University Press, New York, NY.

Hendrickson, O. 2003. Old-growth forests: Data gaps and challenges. The Forestry Chronicle 79 (3): 645-651.

Holling, C.S., F. Berkes and C. Folke. 1998. Science, sustainability and resource management. In F. Berkes, C. Folke and J. Colding (eds.). Linking Social and Ecological Systems. pp. 342-362. Cambridge University Press, Cambridge, UK.

Hunter, M.L., Jr. 1989. What constitutes an old-growth stand? Journal of Forestry 87: 33-35.

Hunter, M.L., Jr. and A.S. White. 1997. Ecological thresholds and the definition of old-growth forest stands. Nature Areas Journal 14(4): 292-296.

Kimmins, J.P. 1997. Balancing Act: Environmental Issues in Forestry, $2^{\text {nd }}$ edition. UBC Press, Vancouver, BC.

Kimmins, J.P. 2003. Old-growth forest: An ancient and stable sylvan equilibrium, or a relatively transitory ecosystem condition that offers people a visual and emotional feast? Answer-it depends. The Forestry Chronicle 79 (3): 429-440.
Merriam, S.B. 1988. Case Study Research in Education: A Qualitative Approach. Jossey-Bass Publications, San Francisco, CA.

Mosseler, A., J.A. Lynds and J.E. Major. 2003a. Old-growth forests in the Acadian Forest Region. Environmental Reviews 11: S47-S77. Mosseler, A., I. Thompson and B.A. Pendrel. 2003b. Overview of old-growth forests in Canada from a science perspective. Environmental Reviews 11: S1-S7.

Moyer, J. 2006. Values and Attitudes toward Old-Growth Forest: A Narrative Study of Leaders in Canada's Forest Sector [thesis]. Dalhousie University, Halifax, NS.

Moyer, J.M., R.J. Owen and P.N. Duinker. 2008. A forest-values framework for old growth [online]. The Open Forest Science Journal 1:27-36. Available at http://www.bentham.org/open/tofscij/openaccess2.htm

O'Brien, E.A. 2003. Human values and their importance to the development of forestry policy in Britain: A literature review. Forestry 76(1): 3-17.

Owen, R. 2006. Old-Growth-Forest Values of Citizen Constituencies in Nova Scotia, Canada [thesis]. Dalhousie University, Halifax, NS.

Rokeach, M. 1973. The Nature of Human Values. The Free Press, New York, NY.

Rubin, H.J. and I.S. Rubin. 2005. Qualitative Interviewing: The Art of Hearing Data, $2^{\text {nd }}$ Edition. Sage Publications, Thousand Oaks, CA. Seidman, I. 1998. Interviewing as Qualitative Research: A Guide for Researchers in Education and the Social Sciences. $2^{\text {nd }}$ edition. Teachers College Press, New York, NY.

Spies, T.A. 2004. Ecological concepts and diversity of old-growth forests. Journal of Forestry 102(3): 14-20.

Steel, B.S. and N.P. Lovrich. 1997. An introduction to natural resource policy and the environment: changing paradigms and values. In B.S. Steel (ed.). Public Lands Management in the West. pp. 3-15. Praeger, Westport, CT.

Vanderlinden, L. and J. Eyles. 2000. Public perspectives on biodiversity: models and a case study. In S. Bocking (ed.). Biodiversity in Canada: Ecology, Ideas, and Action. pp. 237-270. Broadview Press, Peterborough, ON. 